\title{
ELS NOMS ÀRABS DE LA XUFLA (CYPERUS ESCULENTUS L.)
}

\author{
POr \\ PERE BALAÑÀ I ABADIA \\ Y \\ JOSEP GARCIA I FORTUNY
}

Qualsevol manual d'història d'al-Andalus oferirà segurament un nombrós llistat d'espècies vegetals i de conreus que foren introduits a les nostres terres pels musulmans. A més, quasi sempre es dóna la coincidència que també llurs noms respectius provenen de la llengua aràbiga. Per això el cas de la xufla (Cyperus esculentus L.) resulta força curiós, atès que, malgrat relacionat mai que ningú els seus noms català i castellà amb una hipotètica etimologia aràbiga (1), en canvi hom considera indiscutible que el seu conreu, específicament al Sarq al-Andalus, és degut als musulmans (2). Fins i tot s'ha arribat a suggerir que l'orxata de xufles ja era fabricada i consumida a al-Andalus durant I'Edat Mitjana (3).

Per tal de desfer aquesta contradicció aparent, només cal, d'una banda, establir i acceptar científicament el caràcter "silvestre» del cyperus esculentus L. al País Valencià (4), i, de l'altra, destacar que al llarg de la història la

(1) L'estudi més convincent és el de JOAN COROMINES. Diccionario crítico etimológico de la lengua castellana, Madrid, $11,89 a-90 a$, reproduït textualment a JOAN COROMINES I JOSÉ A. PASCUAL, Diccionario crítico etimológico castellano e hispánico, Madrid, II, 402b-403b. La relació semàntica de chufa amb golosina que s'hi estableix, la retrobarem en parlar del habb 'aziz.

(2) "Se cría principalmente en la huerta valenciana, donde fue introducida por los moros" (PIOO FONT QUER, Plantas medicinales. El Dioscorides renovado, Barcelona, 1981 (7), 922 \}.

(3) RACHEL ARIÉ, Remarques sur /'alimentation des musulmans d'Espagne au cours du Bas Moven Age, "Cuadernos de Estudios Medievales" (Granadal, II-III (1974-1975), 306, i RACHEL ARIÉ, España musulmana (siglos VIII-XV), Barcelona, 1982, 287. Tanmateix, ja fa temps que l'aparició de l'orxata de xufles fou datada correctament a mitjan segle XVIII per FRANCISCO ALMELA Y VIVES, Historieta de la horchata de chufas, "Boletín de la Sociedad Castellonense de Cultura", XIV (1933), 68.

(4) Cosa que ja remarcà ANTONIO JOSEF CAVANILLES, Observaciones sobre la Historia Natural, Geografía. Agricultura, Población y Frutos del Reyno de Valencia, Madrid, I, 1795, 141. Vegeu també B. PAS CUAL I J. V. MAROTO. Estudio básico sobre la hipotética latencia de los tubérculos de las poblaciones valencianas de chufa (Cyperus esculentus L.), "Anales del Instituto Nacional de Investigaciones Agrarias" (Madrid), n. ${ }^{\circ} 25$ (1984), 67. 
Ilengua aràbiga ha creat diverses denominacions per a la planta (xuflera) o per als seus tubercles (xufles), amb la qual cosa copsem una certa vacil.lació a l'hora d'identificar amb precisió l'espècie vegetal considerada. Així, sense un caràcter exhaustiu, solament espigolant un ampli ventall de textos de temes variats (Agricultura, Botànica, Farmacopea, etc.), hem aplegat els noms àrabs de la xufla, que presentem aquí ordenats segons l'alfabet aràbic.

\section{Habb al-zalam}

Apareixen també les variants vocàliques habb al-zulam i habb al-zalim (5). La primera citació entre els autors aràbics, la trobem a la traducció catalana (segle XIV) del Kitāb al-adwiyya al-mufrada d'lbn Wäfid (m. 1074) (6):

"E hap açalam es avelana indiana. Dix. D. [ioscòrides] que aquestz son grans menutz com çiurons e sson de bona sabor e es calent en lo tercer grau e val a la dolor de les dentz» (7).

Ibn Wāfid no esmenta la xufla al seu tractat d'agricultura (8), però, com veurem més endavant, li atribueix un altre nom al Kitāb al-wisãd, la qual cosa, pel cap baix, demostra una certa confusió en el mateix científic (9). Observem, a més, que la traducció catalana, "avelana indiana», indica la sensació de trobar-se davant d'una planta d'origen exòtic, que més tard a Castella seria anomenada «juncia avellanada» (10), amb què queda establert ja un creuament entre els conceptes «xufla» i «jonça» que retrobarem sovint.

Poc després que Ibn Wāfid, en un tractat agronòmic, I'autor sevillà AbūI-Hayr al-Sağğăr (final segle XI) (11) devia parlar de la xufla, car la confusió d'aquest tubercle amb èl «pebre negre» (fulful al-sūdān) li és assignada per Ibn al-c'Awwām (12). Malauradament, de l'original àrab d'Abū-1-Hayr tan sols

(5) Respectivament a R. DOZY, Supplément aux dictionnaires arabes, Beyrouth, 1981 (2), 1, 240a, i KAS. PAR BAUHIN, Theatri Botanici sive Historiae plantarum ex veterum et recentiorum placitis, Basilea, 1658 , 223 i 225-226 (formes "Habalzelim, Azelen i Alzelinm).

(6) Les dades biográfiques, en general, procedeixen de Carmen PEÑA, AMADOR DÍAZ et alios, Corpus medicorum arabico-hispanorum, "Awräq" (Madrid), IV (1981), 79-111.

(7) El "Libre de les medecines particulars". Versión catalana trescentista del texto árabe del Tratado de los medicamentos simples de Ibn Wáfid, autor médico toledano del siglo XI, transcripción, estudio proemial y glosarios por LUIS FARAUDO DE SAINT-GERMAIN, Barcelona, 1943, 151, foli $82 b-c$.

(8) JOSÉ M. MILLAS VALLICROSA, La traducción castellana del "Tratado de Agricultura" de lbn Wãfid, "Al-Andalus", VHII (1943), 281-332 (publicat novament, sense la traducció castellana completa amb el títol El "Libro de Agricuitura" de Ibn Wāfid y su influencia en la agricultura del Renacimiento, dins JOSÉ M. ${ }^{a}$ MILLÁS VALLICROSA, Estudios sobre historia de la ciencia española, Barcelona, 1949. 177-195].

(9) Vegeu infra, pel nom sucda cirāqiyya.

(10) COROMINES-PASCUAL, op. cit., 403a, i BAUHIN, op. cit., 224, on diu: "NOMEN... Hispanis \& Lusitanis, lunca auellanada, Ciafas" (mala grafia evident de "ciufas»).

(11) ARIÉ, España musulmana, 221, diu que uestudiaba en Sevilla en el año 494/1100", sense aportar-ne documentació Sobre aquest autor, cf. JOSÉ M. MILLÁS VALLICROSA, Aportaciones para el estudio

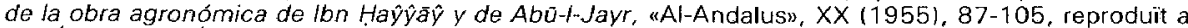
JOSE M. MILLÁS VALLICROSA, Nuevos estudios sobre Historia de la ciencia española, Barcelona, 1960, 153-171 (vegeu especialment les pp. 101-105 i 167-171, respectivament).

(12) Vegeu la nota 16 i el seu context. 
en coneixem alguns fragments que no han estat editats (13).

La xufla també fou anomenada habb al-zalam per lbn Buklāriš (segona meitat del segle XI-inicis del XII) dins Al-Mustacini (14), obra de la qual hom en prepara actualment l'edició i traducció (15).

En arribar al final del segle XII, al seu famós Kitāb al-Falāha, el també sevillà Ibn al-cAwwām diu així: "Del habbozalem [habb al-zalam] que según Jair (16) es la pimienta negra. Esta es cierto grano semejante á la haba dulce, el cual es blando mientras se mantiene fresco, y muy dulce cuando se ha secado, si bien un poco duro. Le conviene la tierra blanda, la caliente, la arenis$c a$, la dulce ligera y suave y la engrasada, $y$ no le conviene la gruesa por su viscosidad. Siémbrase en Abril con estaca del mismo modo que las habas en tablares labrados, abonados con estiércol repodrido, y refrescados y bien humedecidos con el agua, poniendo sus granos en ellos ordenados en filas $y$ á dos dedos de distancia uno de otro sembrando en diez tablares poco mas de una libra. Sembrándola también encima de los caballones que hay entre los tablares y en los de las regueras, prevalece. Arráncase en Octubre y el modo de hacerlo es humedecer con el agua la tierra en que se había sembrado y recalada esta medianamente, coger la planta por las hojas y arrancárla con toda su raiz y sacudiéndola en la tierra recoger el granon (17).

Durant la primera meitat del segle XIII parla del habb al-zalam el cèlebre Ibn al-Bayțār (Màlaga, 1197-Damasc, 1248) al Kitāb al-ğamīc li-mufradāt aladwiya wa-l-aǵdiya. Diu la traducció francesa publicada (18):

"Habb ez-zelm, Cyperus esculentus.

IBN OUAFED. C'est une graine grasse et aplatie, un peu plus grosse qu'un pois chiche, jaune en dehors et blanche en dedans, d'une saveur agréable et délicate. On l'apporte du pays des Berbères. On l'appelle chez nous poivre des nègres, fulful al-südān, mais le poivre des nègres est en realité autre chose (19). - IBN MASSAH EL-BASRY. Le hab ez-zelm est chaud au troisième

(13) MILLÁs, Nuevos estudios, 169-171

114) DOZY, op. cit., loc. cit. Habb al-zalam, tanmateix, no és emprat al pròleg de l'obra. Cf. ANA MAR[A LABARTA GÓMEZ, El prólogo de Al-Musta ${ }^{\mathrm{I}}$ ni de lbn Buklâriš según los manuscritos de Madrid y Nápoles. Transcripción, traducción v estudio, tesina de llicenciatura inèdita, Barcelona, 1972, $221 \mathrm{pp}$.

115) Cf. PEÑA, DIAZ et alios, op. cit., 87a.

(16) Sobre la identificació d'aquest «Jair» amb Abū-1-Hayr al-Sağğâr al-Iకbbiti i les citacions freqüents que de la seva obra fa ibn al-cAwwām, cf. MlLLAS, Nuevos estudios, 167-168.

(17) Libro de Agricultura. Su auftor el doctor excelente Abu Zacaria lahia Aben Mohamed ben Ahmed Ebn El Awam, sevillano, Sevilla-Madrid, 2 vols., 1878, 1, 406

(18) Traité des simples par lbn el-Beithar, trad. L. Leclerc, Paris, 1877, 1, n. ${ }^{\circ}$ 559, 395-396.

(19) L'expressió chez nous ha d'interpretar-se com «a al-Andalus». Hem vist que Ibn al-cAwwãm atribuia la confusió a Abü-l-Hayr, però també és possible que lbn Wāfid de Toledo conegués el tractat del seu contemporani Abū-l-Hayr (vegeu la nota 11 ) i se'n fes ressò en una obra que no és ni la que fou traduĩda al català (Libre de les medecines particulars), ni els seus "Compendi d'Agricultura" o Kitáb al-wisád. Per això nosaltres pensem que la citació recollida per lbn al-Bayțãr podria correspondre a una obra perduda (o desconeguda) d'Ibn Wāfid. Sobre tota aquesta problemàtica, cf. PEÑA, DIAZ et alios, op. cit., 85-86, i, sobretot, amb una bibliografia quasi exhaustiva, CAMILO ALVAREZ DE MORALES Y RUIZ MATAS, "El libro de la almohada" de lbn Wâfid de Toledo (recetario médico árabe del siglo Xl), Toledo, $1980,21-23$. 
degré et humide au premier. II seconde activement la sécrétion spermatique. Il est agréable au goût et croît dans les environs de Cheherzour. - LE CHÉRIF. Mâché et appliqué sur les lentilles de la face, il les fait disparaître. On le remplace par le graine de chekakol (tordylium)".

De nou veiem esmentat el habb al-zalam dins l'obra principal del metge oriental Dāwūd ibn "Umar al-Anțākī (mort a La Meca I'any 1599) (20). Aquest diu textualment: «Habb al-zalam. Engreixa el cos, cura la debilitat dels ronyons (21) i augmenta la potència sexual. La millor manera d'usar-lo per a l'engreixament consisteix a moldre'l i deixar-lo en remull en aigua durant una nit. Després s'escorre, es cola i es beu [el suc] amb sucre» (22).

Finalment, la xufia apareix amb el nom de habb al-zalam a la Tuhfat al$a h b a ̈ b$, glossari marroquí de la primera meitat del segle XVIII (23) que remet a "habb "aziz "graine précieuse" ". I'altre nom àrab de la xufla més divulgat. Els editors l'identifiquen amb els "Tubercules du souchet comestible", però afirmen que, al Marroc, tan sols han pogut trobar els tubercles del Cyperus rotundus $L$., és a dir, de la planta anomenada $s u^{c} d$ en llengua aràbiga (24).

Per enllestir aquest apartat sobre el habb al-zalam, diguem que els diccionaris actuals recullen la seva accepció de "xufla" fins $i$ tot en la llengua àrab moderna (Freytag, Dozy, Beaussier i Blachère, per exemple).

\section{Habb (al-) $)^{c} a z \bar{z} z$}

Segons Dozy és més correcta la forma sense article, que ha originat una etimologia popular segons la qual la xufla tindria aquest nom àrab perquè els tubercles li agradaven molt al sobirà fatimí al-c $\mathrm{A} z \bar{i} z$ ibn al-Mucizz (25). Avui dia, a Síria, hom anomena habb caziz indistintament la calamarsa i uns caramels petits i rodons (les "golosinas") amb què sembla tenir més consistència la proposta etimològica de Coromines respecte al mot castellà "chufa» (26).

Entre els autors "clàssics", recullen aquesta denominació de la xufla Ibn al-Bayțār i al-Anțākĩ. Diu el primer: «Habb al-cazīz. Habb el-a'zīz [identificat per l'editor amb ell CYPERUS ESCULENTUS. C'est le habb ez-zelm, dont il

(20) Sobre l'autor i la seva obra, cf. l'aticle de C. BROCKELMANN i J. VERNET, a El (2), 1, 53 1b, i MAX MEYERHOF, Esquisse d'histoire de la pharmacologie et botanique chez les musulmans d'Espagne, "AlAndalus", III (1935), 36.

(21) Propietat per la qual els àrabs medievals confonien sovint la xufla amb la jonça (sucda) de què hom predicava la mateixa virtut. Cf. El "Libre de les medecines particulars", 102, foli $52 b$.

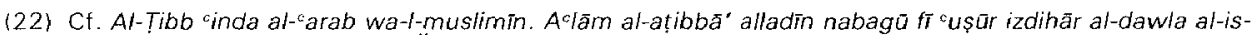
lāmiyya, "Ahlan wa-Sahlan» (Gidda), IX, n. ${ }^{\circ} 4$ (abril 1985), 19.

(23) Tuhfat al-ahbāb. Glossaire de la matière médicale marocaine, ed. i trad. de H. P. J. Renaud i Georges S. Colin, París, 1934, n.* 189, 84-85.

(24) Ja hem vist que la confusió entre el cyperus esculentus $L$. (babb al-zalam o habb aziz) i el cyperus rotundus $L$. (s $u^{c} d$ o $s^{\circ} d a$ ) és quasi proverbial eıtre els científics àrabs medievals

(25) Cf. DOZY, op. cit., 1, 240a, i Al-Tibb cinda al-carab, 19.

(26) informació oral del doctor KAMAL KHER, metge sirià que exerceix avui dia a Barcelona. Vegeu també abans la nota 1. 
vient d'être question. Il en croît en Égypte, au Sâid, où on lui donne le nom de sakit, al-saqit? (27).

Quant a al-Anțākĩ, dins la seva obra principal, la cèlebre Taḍkira Dāwūd, apareix el nom amb article (habb al-caziz) com a sinònim de habb al-zalam. El comentarista del text original diu que la xufla també és anomenada al-sacar i que "és receptada a les dides; de les seves llavors s'extreu un oli dolç que calma i beneficia les fissures de mamella (la mastitis) » (28). I encara afegeix que actualment a Àustria hom en beu el suc com si fos llet i que a Espanya se'n prepara una beguda refrescant, és a dir, l'orxata.

Alguns diccionaris moderns (Dozy, Beaussier, Wehr) inclouen la forma amb article; d'altres (Freytag, Blachère), la que no en duu. En conjunt predomina, però, el nom habb caziz, que sembla l'expressió actual més extesa dins el món àrab per designar el Cyperus esculentus $L$. A més, així ho han copsat els botànics europeus entre els segles XVII i XX (Bauhin, Forskâl, Bustinza) (29).

\section{Zalam}

Tots els textos que recullen aquest nom àrab de la xufla (Dozy, Tuhfat al-ahbāb) deriven de l'obra clàssica d'Ibn al-Bayțãr, en què llegim: "Zelm [identificat pel traductor amb el] CYPERUS ESCULENTUS. C'est une plante qui ressemble à une tige mince et au dîs. Elle n'a pas de graines, mais de racines abondantes et souterraines portant des graines aplaties d'une saveur sucrée. On les mange et on leur donne le nom de habb ez-ze/m. Elles sont bien connues chez nous en Andalousie et dans le Maghreb extrême sous le nom de poivre des Nègres, fulful al-südān. On sème la plante, qui se trouve abondamment à l'état sauvage (30) dans les Zâb de la province d'lfrîkiya. Il y en a une espèce blanche et une noiren (31).

És clar, doncs, que hom distingeix la xuflera (zalam), planta, dels seus tubercles o xufles (habb al-zalam). En aquest sentit, algunes enciclopèdies aràbigues actuals donen com a sinònim de.xuflera la forma plural de zalam, 0 sia, azlām, que tal vegada podríem traduir directament per «xufles» (32).

(27) Traité des simples, I, n. ${ }^{\circ} 560,396$. La presència del cyperus esculentus L. a Egipte, amb el nom Hab el ażiz, és atestada per PEHR FORSKẤ, Flora Aegvotiaco-arabica, sive descriptiones platarum, quas per Aegymtum inferiorem ad Arabiam felicem detexit, Kopenhagen, 1775, LXo 56. Ibn al-Bayțār, peró, no dedica cap apartat al nom al-saqit, que tractarem més endavant $\left(n \cdot{ }^{\circ} 7\right)$.

(28) Al-Tibb cinda al-carab, 18-19. Sobre al-sacar, vegeu més endavant el nostre número 6

(29) Cf. BAUHIN, op cit., 226 (variants Habaziz, Habel Aßis, Alzis i Abaziz); FORSKÂL, op. cit., loc. cit: (Hab el aziz); i FLORENCIO BUSTINZA, Contribution à l'étude des ferments du Cyperus esculentus $L$., "Bulletin de la Société Botanique de Genéve», XXI (1929), 198 (hab-el aziz). Aquest científic, curiosament, havia experimentat amb xufleres procedents de la provincia de Tarragona

(30) Ibn al-Bayțār constata el caràcter de "mala herba» de la xufla, al qual ens hem referit abans. Vegeu la nota $4 \mathrm{i}$ el seu context.

(31) Traité des simples, II, n. ${ }^{\circ} 1.120,215$. Ibn al-Bayțār és el primer tractadista àrab que identifica més d'una espècie de cyperus esculentus $L$.; actualment hom en reconeix més de quatre-centes.

(32) Al-Mưğam al-carabi al-hadit Lărus, París, 1973, 629b. 


\section{Sưda irãqiyya}

Com a variants del substantiu apareixen $s u^{c} d$, sacdā i suldà; l'adjectiu que hi concorda pot ésser masculí: 'irāqĩ. De fet, la sucda quasi sempre és identificada amb la jonça o cyperus rotundus L.; pero la gran semblança d'aquesta subespècie de les ciperàcies amb la xufla fa que s'hagin confós ambdues, ja des de I'Antiguitat. Així, al Dioscòrides-Laguna, sota la rúbrica de Cypero s'hi amaguen indistintament el cyperus esculentus $L_{\text {., }}$ el cyperus longus $L$. i la curcuma longa $L$., la qual ni tan sols no és una ciperàcia (33).

Dozy diu: "Sudà (les voyelles dans les Gl. Manc.) pl. sudayāt souchet Cyperus [identifica només la família, no una espècie concreta], de même que $s u^{c} d$; la meilleure espèce est celle de Coufa, qu'on appelle aussi sucda cirãqiyya, puis celle d'Egypte; il y en a aussi d'autres's (34).

Ara bé, quan aquest mateix diccionari diu que Pedro de Alcalà tradueix "cûdde" per "juncia avellanada", atès que aquest, com hem vist, era el nom medieval castellà de la xufla, ens expliquem per què l'editor del Kitāb al-wisãd ha distingit $s u^{c} d$ i $s u^{c} d a$, que tradueix per "Juncia (Cyperus longus)", de $s u^{c}$ dà irāqi, que identifica sistemàticament amb el cyperus esculentus, bé que al text castellà no escriu mai "chufa» sinó «juncia iraquí. Per tant, Ibn Wãfid, autor del "Libro de la almohada», segons això anomenava indistintament habb al-zalam i sucidà cirāqi la mateixa espècie vegetal (35).

En canvi, l'editor del text d'Ibn 'Abdün (Sevilla, final segle XI-inici del XII) identifica al-sucdà al-cirāqiyya, de la qual diu que en llatí rebia el nom de yunğa wartayra, o sigui, jonça d'horta o conreada, amb el cyperus longus $L$. o el cyperus rotundus $L$. (36). I, encara, Ibn al-Baytāar fa equivaler el $s u^{c} d$ amb el cyperus rotundus $L$., fent constar que "On lit dans une note de la traduction arabe de Dioscorides que cette plante s'appelle en latin ioundjou (sic)" . Però l'editor, que acaba de dir això, decideix traduir el mot àrab per souchet odorant, és a dir, la jonça olorosa, que en un altre indret trobem identificada amb el cyperus longus L. (37).

De tot aquest embolic només destaquem, per acabar, que sucda cirã-

(33) Cf. FONT QUER, op. cit., 924; i CÉSAR E. DUBLER, La «Materia Médica» de Dioscórides. Transmisión medieval y renacentista. Vol. III: La «Materia Médican de Dioscórides traducida y comentada por $D$. ANDRES DE LAGUNA (Texto crítico), Barcelona, 1955, 14-15. Laguna escriu Sadh, com a sindnim de cyperus, forma que segurament és una metàtesi de Sahd, o sia, sac o o sucd (notes de Dubler al cap. IV).

(34) DOZY, op. cit., I, 654a.

(35) Vegeu abans la nota 10 i el seu context. A més, cf. CAVANILLES, Observaciones, 141: "La juncia avellanada, llamada vulgarmente chufas, y por Linneo cyperus esculentus»; i també, del mateix autor, De la Juncia avellanada, ó Chufas de Valencia, "Anales de Ciencias Naturalesn (Madrid), HI (1801), 234. Per al text d'lbn Wäfid, cf. ÁLVAREZ DE MORALES, op. cit., 390.

(36) Cf. PEÑA, DÍAZ et alios, op. cit., 87 b; i MIGUEL ASÍN PALACIOS, Glosario de voces romances registradas por un botánico anónimo hispano-musulmán (siglos XI-XII), Madrid-Granada, 1943, 364. També LABARTA, op. cit., 139, nota 204.

(37) Traité des simples, 11, 253: i ASIN, op. cit., 364, n. ${ }^{\circ} 679$, YUNCHA FINA UARTAIRA = juncia olorosa o redonda. 
qiyya és un dels noms atribuïts a la xufla en un dels estudis més recents, el qual se suposa que ha tingut en compte la bibliografia precedent.

\section{Sucda bustäniyya}

Aquest nom de la xufla, que significa literalment «jonça (o cyperus) del jardí (o de l'hort)", només apareix a l'obra d'Ibn 'Abdūn: "Sucdà cirāqivya: y se la llama..., como los cayam [els estrangers] (38) la adjetivan, fina, es decir, estera o alfombra. En latín se llama yuncha [per yunğa] uartaira [per wartayra], o sea, sucdà bustaniyya» (39). I el traductor explicita aquesta denominació dient que equival a ujuncia hortense».

\section{Sacar}

No podem assegurar que aquesta sigui la vocalització exacta del mot, que trobem en un text sense vocalitzar $(40) \mathrm{com}$ a sinònim actual de "xufla". Ara bé, si correspon al «Saherade» que Laguna admet en lloc de $s a^{c} d$ o $s u^{c} d$ i, en definitiva, del llatí cyperus, castellà juncia olorosa, català iunça (jonça) i francès souchet, aleshores sacar podria documentar-se ja pràcticament a partir dels temps medievals (41).

Pel que fa al significat del mot, un cop consultats els diccionaris àrabs més coneguts, ens podem decantar per una d'aquestes dues possibilitats: a) $S a^{c} a r$ es relaciona amb un color que "tira al negre» (42) i, per tant, la xufla seria "el [tubercle] negrenc o negrós», d'acord amb la realitat botànica; b) Sacar deriva d’una arrel aràbiga molt fructífera en temps medievals, que Pedro de Alcalá vincula a la idea genèrica de "glotonear, golosear" (43). Aleshores traduiriem sacar per golosina o llaminadura, conceptes dels quals, com ja hem vist, deriva el mot castellà "chufa" (44).

\section{Saqit}

També trobem documentada la variant diminutiva suqqayt (45), conforme amb el volum dels tubercles de la xuflera, definits quasi sempre com ude

(38) O sia, els habitants de la península ibèrica que parlaven una llengua romànica, derivada del llatí.

(39) Cf. ASÍN, op. cit., 334, n. ${ }^{\circ} 621$ VIBNA MAYOR = juncia Jarga: "sudà, que es el cyperus longus $L$., la juncia larga u olorosa de Colmeiro"; també pàg. 364, on, en canvi, "Sucdà... es la juncia olorosa (cyperus longus L. 10 la juncia redonda (cyperus rotundus $L$.). La confusió, doncs, es transmet fins als nostres dies.

(40) Al-Tibb cinda al-carab, 19.

(41) DUBLER, op, cit., III, 14.

(42) Cf. Al-Mǔğam... Lãrũs, $622 b$, que vocalitza al-sacar considerant el mot com un mașdar de la primera forma verbal.

(43) DOZY, Op. cit., I, 655 a. Encara el valor de voracity és recollit avui dia al diccionari de Wehr per a sucr i sucăr.

(44) Vegeu supra, nota 1.

(45) DOZY, op. cit., 622a, el qual remet al diccionari de Lane i a Ibn al-Bayțăr (vegeu la nostra nota 27 ). 
la mida de cigrons, faves o avellanes petits" (46). Atès que la informació procedeix d'lbn al-Baytāar (vegeu l'apartat habb 'azizl) i que el mot no és vocalitzat, potser calgui lleguir directament suqqayt o al-suqqayt (47). Actualment, tant al-saqüt com al-suqqayt han perdut el significat de "xufla» en l'àrab col.loquial egipci, però, en canvi, saqît i saqā'it designen la «calamarsa" (48), amb què ja podem recordar novament el que dèiem respecte a habb caziz.

\section{Sinn al-cağūz}

El traductor i intèrpret Fārūq Muḥammad al-Ra'îs, domiciliat actualment a Barcelona, ens manifestà que desconeixia els mots saqit o suqqayt amb el significat de "xufla". En canvi, va informar-nos que el nom vulgar d'aquest tubercle a diversos països àrabs és avui dia $\operatorname{sinn}$ al-cağuz, és a dir, literalment, "dent de vella (o de vell)», expressió molt popular i gràfica, atesa la semblança de les xufles amb les dents petites i negroses. D'una altra banda, en la terminologia aràbiga científica, tant per a la zoologia com per a la botànica, l'ús d'expressions compostes amb el mot sinn (plural asnān) és molt freqüent (49).

A la bibliografía consultada, no hi hem trobat mai aquest nom aplicat a la xufla en temps medievals, però creiem que és emprat un cop per lbn Wāfid al Kitāb al-wisād, malgrat que l'editor no ha pogut identificar-lo. En una recepta per a un dentifrici, i recordem que, segons el mateix lbn Wāfid, el habb al-zalam o xufla "val a la dolor de les dentz» (50), llegim textualment:

"Dentífico (sic) para fortalecer la encía y limpiarla.

[Se toma] una uqiyya de rosa, media de semillas de acedera, otra media de maná de bambú, igual de nuez de areca, otra media de flor de granado, otra media de nuez de agalla sin perforar, un tercio de uqiyya de sukk e igual de dientes de ternero (17), un mithqal de la parte más pura de la galena, otro de coral calcinado, igual de arcilla de Armenia y la misma cantidad de madera de agáloco. Se pulverizan por separado, se reúnen luego y se usa el preparado" (51).

A la nota número 17, l'editor diu: «Ningún glosario ni repertorio botánico citan esta palabra. Aparecen varias plantas con el nombre de dientes de perro, dientes de león y lengua de buey. Quizás pudiera tratarse realmente de

(46) Cf. IBN BAȘȘĀL, Libro de Agricultura, editado, traducido y anotado por JOSÉ M. ${ }^{a}$ MILLAS VALLICROSA y MOHAMED AZIMAN, Tetuán, 1955, 190: "Su simiente se parece al haba en cuanto at tamaño»; cf. també DUBLER, op. cit., III, cap. 5, 15: «Se llama... juncia avellanada en Castilla, por parecerse en figura, y en sabor, a las auellanas mondadasn.

(47) Tal com va fer DOZY, op. cit., 662a; però els diccionaris moderns de Wehr i de Kazimirski atribueixen a saqịt el valor semàntic de "calamarsa" y no parlen del diminutiu.

(48) Sagit no apareix a Socrates SPIRO, An Arabic-English Dictionary of the Colloquial Arabic of Egypt, Beirut, 1973, 281b. Quant al significat de calamarsa, a més de les referències de la nota anterior, cf. AlMưğam... Lärùs, 667a.

(49) DOZY, op. cit., 1, 689.

(50) Cf. El «Libre de les medecines particularsn, 151, foli 82b-c; també aquí, a l'apartat n. 1 (habb al-zalam).

(51) Cf. ÁlvareZ DE MORALES, op. cit., 124 
los dientes del animal, aunque en tal caso parecería lógico que le siguiese alguna indicación como pulverizados o calcinados, o algo similar, cosa que no sucede» (52).

Com es pot comprovar als índexs de l'edició (pp. 376 i 420), aquesta substància només és esmentada un cop, i l'autor ha llegit al manuscrit l'expressió asnān al-ciğl, "dents de vedell». Ara bé, atès que el lām final pot ésser confós fàcilment en un manuscrit àrab amb un zāy el punt superior del qual s'hagi unit al cos de la lletra, nosaltres crejem que s'hauria de llegir asnā n al- ${ }^{c} u g ̆ u z$, o sigui, "dents de vells», denominació, com hem vist, gràfica i popular de les "xufles». Si la nostra argumentació és correcta, tindríem documentat l'ús medieval del nom, el qual podria ésser incorporat als diccionaris escaients com a terme botànic corresponent al cyperus esculentus $L$. (53).

\section{Fulful al-sūdān}

Ibn al-cAwwām, que aprofita indistintament els tractats agronomics d'Abü-l-Hayr i d'Ibn Bașșāl, com hem dit abans atribueix al primer la confusió entre el habb al-zalam i el fulful (o filfill) al-sūdān. Tanmateix, com que a l'obra d'Ibn Bașșāl, el qual no cita, però, la procedència, quan es parla de la upimienta del Sudán» de fet s'explica el conreu de la «xufla», hem de deduir que Abū-l-Hayr pertanyia cronològicament a una generació anterior a la d'Ibn Bașșāl (54). Diu aquest, seguint Abū-l-Hayr:

"Cultivo de la pimienta del Sudán.

Prepararemos la tierra del modo que en otros cultivos hemos explicado, la regaremos a fin de que ella se enfríe, y se sembrará después de ésto como se siembran las habas: en cada tablero habrá tres líneas a lo largo, y entre una y otra simiente habrá una distancia de dos pulgadas, pues es una planta blanda y suave; su siembra se efectuará en el mes de abril y se cosecha en el mes de octubre. Para ello se arranca con todas sus raíces, se golpea con ella la tierra y se recogerá el grano que se desprenda. Le conviene la tierra negra, estercolada, la suelta y arenosa; no le conviene la tierra gruesa, por razón de que ella se adhiere con la raíz y no se desprende cuando se pega al suelo.

Su simiente se parece al haba en cuanto al tamaño, si bien es dulce, blanda y mejor de gusto cuando está seca; se come cuando está verde, y entonces

(52) Ibidem, 124, nota 17

(53) Al de DOZY, per exemple, ja que mai no va poder citar Ibn Wäfid de primera mà

(54) Segons DOZY. op. cit., 11, 279b, el fulful al-sūdān és efectivament la xufla, ja que diu: «Au Maghrib. les racines du souchet comestible, amandes de terre», adduint l'autoritat d'ibn Buklāriš, Ibn al-Baytãr i Ion al-cAwwām. Però l'editor d’ibn al-Baytār identifica la planta amb la Unona aethiopica, i cita lbn Wăfid, el qual afirma que el nom berber del fulful al-sūdān es ḥarmī (cf. Traité des simples, III, 43-44). Per això insistim que deu existir una obra encara desconeguda d'Ibn Wãfid (vegeu la nota 19). Per que fa a la cronologia, Abū-l-Hayr no era de la generació umisma o inme diatamente posterior a la de Ibn Bașşâlı (MILLÁs, Nuevos estudios, 151), sinó contemporani d'lbn alHağğăğ (vers 1073-1074), mentre que lbn Bașșäl ho fou alhora d'lbn Wáfid (m. 1074), Ibn 'Abdūn (m. inici del segle Xli) i d'al-Tignarī (m. segle XII, desprês d’lbn Bașșäl). Cf. Ibidem, 127 i 134, i JOSÉ M. MILLAS VALLICROSA, Un nuevo manuscrito de la obra agronómica de al-Tignari, "Tamuda", I (1963), $85-86$. 
su gusto se parece al de la castaña verde. Es una planta que no se mantiene sobre un tallo o pie, ni hace espigas ni botones, sino sólo produce el fruto en las raíces. Cuando nace se parece a la cebadan (55).

Només cal comparar aquesta citació amb el text que ens ha transmés Ibn al-cAwwäm sobre el habb al-zalam ("habbozalem») per comprovar que la planta de què hom parla és la mateixa "xufla». En definitiva, doncs, la confusió que ja detectà Ibn al-Bayțăr devia originar-se al tractat agronòmic perdut d'Abū-l-Hayr al-Sağğār (56). I tot aquest seguit de confusions ens permet de pensar amb fonament, per acabar, que la xufla no fou introduïda a al-Andalus pels musulmans (57).

(55) Cf. IBN BAȘŞĀL. op. cit., 189-190. El text forma part del acapitulo Xlll... destinado a las plantas bulbosas $y$ raices" (cf. MILLAS. Nuevos estudios, 144 l.

(56) Ibidem, 151 i 167.171. En síntesi, Ibn Wäfid de Toledo (m. 1074) i Abū-l-Hayr de Sevilla (m. després de 1100 ) devien ser pràcticament contemporanis (durant el tercer quart del segle $X 1$ ) i devien conèixer llurs tractats agronómics respectius.

(57) Fem constar aquí que el sistema de transliteració de la llengua aràbiga emprat en aquest article és el de la Gran Enciclopèdia Catalana (GEC). L'estudi ha estat dut a terme bàsicament al Departament d'Estudis Medievals del C. S. 1. C. a Barcelona, al personal investigador $i$ administratiu del qual devem molta ajuda, aixi com al senyor Eugeni Sierra i Ràfols, director del Jardí Botànic de Barcelona, i a la senyora Teresa Formentí, bibliotecària de l'Institut Botànic. La seva col.laboració ha estat, certament, inestimable. 